\title{
The transient stability analysis of wind turbines interconected to grid under fault
}

\author{
Anass Gourma, Abdelmajid Berdai, Moussa Reddak \\ Electrical Engineering Department, Hassan II University, \\ National Superior School of Electricity and Mechanics (ENSEM), Casablanca-Morocco
}

\begin{tabular}{|c|c|}
\hline Article Info & ABSTRACT \\
\hline Article history: & Wind farm has been growing in recent years due to its very competitive \\
\hline Received Apr 8, 2019 & to megawatts. However, the participation of the wind turbine in the stability of \\
\hline Revised Aug 31, 2019 & the electricity grid is a critical point to check, knowing that the electricity grid \\
\hline Accepted Sep 27, 2019 & is meshed, any change in active and reactive flux at the network level affects \\
\hline Keywords: & $\begin{array}{l}\text { grid, the stability of the rotor angle is a dynamic phenomenon which is only } \\
\text { visible by the variation of the active energy. The purpose of this journal is to }\end{array}$ \\
\hline DFIG & verify the impact of wind turbine integration on an electrical grid, \\
\hline Reactive flow & the Doubly Fed Induction Generator equipping most wind energy systems, and \\
\hline Rotor angle & the stability of the rotor angle of the synchronous generators equipping \\
\hline Transient stability & the conventional power plants in the electrical system. \\
\hline villic & $\begin{array}{r}\text { Copyright }(\odot) 2020 \text { Institute of Advanced Engineering and Science. } \\
\text { All rights reserved. }\end{array}$ \\
\hline \multicolumn{2}{|l|}{ Corresponding Author: } \\
\hline \multicolumn{2}{|c|}{$\begin{array}{l}\text { Anass Gourma, } \\
\text { Electrical Engineering Department, } \\
\text { National Superior School of Electricity and Mechanics (ENSEM), } \\
\text { Road El Jadida, Km 7, BP : 8118, Oasis-Casablanca, Morocco. } \\
\text { Email: anassgourma@ hotmail.fr }\end{array}$} \\
\hline
\end{tabular}

\section{INTRODUCTION}

The high rate of penetration of electricity produced by wind turbines into electricity grids is a serious challenge for power grid operators, because of their volatility and intermittency, the addition of a rotating reserve or the additional available capacity provided by the generators is a more than favorable solution for $90 \%$ of the time in order to establish the balance between production and consumption [1-2]. Here comes the doubly fed induction generator (DFIG) that can generate electrical energy in several intervals and a high production of $30 \%$ compared to the conventional generator with a suitable command [3]. However, the electrical network must be able to maintain its electrical stability during the various faults occurring on the network [4].

By injecting a wind turbine into a given location, the network must be able to handle the conjectures of the electrical powers $[5,6]$. In fact, the active energy produced by the DFIG contributes to the stability of the rotor angles of conventional generators and whose variation largely impact the electrical system [7], but the reactive energy provided by the DFIG remains critical for these synchronous generators equipping conventional power plants [8,9]. In fact, the results of works in paper [10] shows that fault occurring in electrical grid has the greatest impact on generator swinging. When such a fault occurs, large currents and torques are produced, and action must be taken quickly if system stability is to be maintained. A decoupled control of the active and reactive energy injected by the DFIG can mitigate the reactive flow of the synchronous generators and minimize the angular instability of the electrical grid [11-12]. 
The results of works in paper [13] showed that with a penetration rate of less than $50 \%$, the DFIG contributes to grid stability due to its low rate of reactive energy consumption during disturbances. Another paperwork [14] showed that with a STATCOM FACTS equipping the power control system of a wind turbine, it allows a better control of active and reactive energy generated by the DFIG and improve the stability of the network. As for the other works [15] published by D. Gautam, V. Vittal and T. Harbor, they demonstrated that DFIG participates in the transient stability of the electricity grid relative to a fixed speed generator, when the system responds to the small disturbance, but may have a negative impact on larger disturbances. The methods discussed above remain limited because they only apply to a specific case. Moreover, the existing structure of the electrical grid is meshed and requires to calculate all types of shorts circuits to define the most critical, also they are based on calculation of the power flow which is not compatible with the active and the reactive regulation.

Our contribution in this research is to verify the impact of the $50 \%$ penetration rate of the DFIG on the stability of the rotor angles on synchronous generators, of the conventional power plants in electrical system during the most critical faults. By simulating the transient regime based of optimal load flow calculation, we will show how the DFIG can interact with conventional generators by dealing with the power angle relationship; indeed, the DFIG behaves like a constant source of energy with a negative impedance during a single-phase fault. The performance of synchronous generators can be improved when wind farms based on DFIG are added with a rate of $50 \%$. First, we will give a detailed description of the impact of high penetration rate of wind farm on the power grid. Second, we will present the adopted system to integrate a wind farm in the electrical grid. Third, we will perform a simulation of system performance using the RTE IEEE 9-bus standard electrical network in order to evaluate the transient stability impact of the DFIG. Finally, we will assess grid stability impact after injecting the wind farm analyzing the active, reactive energy and the rotor angle of the DFIG during the transient regime.

\section{PROBLEM FORMULATION}

\subsection{Impact of wind turbines high penetration rate on the main voltage and frequency}

The production of the wind generator is proportional to the cube of the wind speed [16]. Knowing that this speed is volatile, this requires a variable and not storable production of active and reactive. In addition, from a high penetration rate, wind farms contribute to frequency fluctuations and voltage instability [17-18]. When faced with these problems, the wind turbines are then equipped with an active and reactive control system, in particular variable speed wind turbines such as DFIG [19]. In fact, the turbines can control their rotation speed according to the wind speed, which reduces the fluctuations of generated power [20]. They also increase the energy captured at low wind speed. The speed increases and decreases slightly during a burst and the resulting of electrical power is effectively filtered by the inertia of the turbine [21]. Thus, any disturbance needs to be filtered. Otherwise, the conventional types of wind turbines can directly transfer these fluctuations to the electricity grid [22].

The voltage variation at the connection point of wind turbine following the active and reactive injection is deduced from the following equation [23]:

$$
\Delta V=\frac{R\left(P_{W}-P_{L}+P_{G}\right)+X\left( \pm Q_{W}-Q_{L}+Q_{G}\right)}{V}
$$

with:

$R, X$ : Being the total resistance and the total reactance of the line

$P_{W}, Q_{W}$ : Being the active and reactive powers provided by the wind turbine

$P_{L}, Q_{L}$ : Being the active and reactive consumption powers

$P_{G}, Q_{G}$ : Being the active and reactive grid powers

The critical problem for the operator or the manager of the electricity network during interconnexion with a wind turbine lies in the obligation to define algorithms, so that the wind turbine remains connected to the network after any electrical failure [24], like a capacity of transmission during outages. Currently, all wind turbines have protection systems that trigger the turbine during a breakdown [25-26]. This essential equipment causes increasing pressure on auxiliaries and reliability standards. Indeed, the contribution of wind turbines in the case of windy and weak wind is modest but is very advantageous. When the penetration rate is considerable, it will no longer be possible for the wind to disconnect the turbines during voltage or frequency disturbances [27], which would result in a significant production deficit. The impact of wind turbine on voltage grid is visualised on Figure 1. 


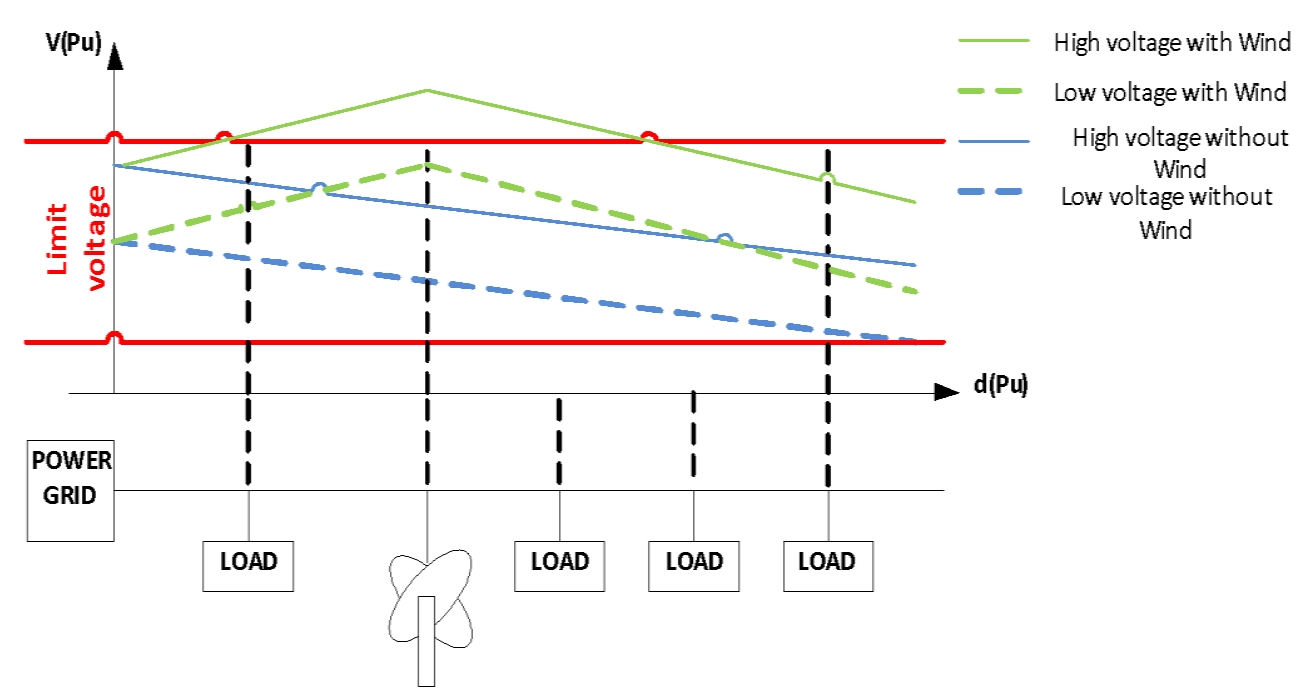

Figure 1. Effects of wind turbine integration on voltage grid

\subsection{Optimisation of DFIG intégration}

The calculation of optimal power flow is used to perfom power system, using voltage and power measurement, it can solve the problem of the active and reactive energy produced by wind farm [28], in fact the classical method based on load flow calculation does not take into account the limits of reactive power in lines and power plants, these constraints can however be programmed in power flow solvers ,in fact the reactive power capability of DFIG can play the role of reactive power compensation devices if the operating system limits the outpout of the wind farms [29]. In our case, we assumed that an independent producer is managing the $50 \%$ penetration rate of the wind farm.

\subsection{Active Energy Analysis}

The purpose of this analysis is to carry out the transient simulation of active energy produced by all the generators of the IEEE 9 Bus network. During Three-phase two-phase and single-phase short-circuit faults, at time $\mathrm{t}=1 \mathrm{~s}$, this simulation will be our reference. Then we will integrate a DFIG represented by a wind farm with a fixed power factor of 0.8 , which will replace a synchronous generator of $163 \mathrm{MW}$. Synchronous generators are modeled to visualize the impact of variable sources on fixed sources. The power factors will be set to 0.8 as well. As a result of their intermittency, wind farms produce variable active energies to the grid, which impacts the active flux at the point of interconnection. This flow variation affects the direction of the active flow in the interconnection lines. This is an advantage in terms of loss limitations but a disadvantage in the strong strangling section areas.

The particularity of the DFIG lies in its rotor which is controlled so that the combined speed of the rotor and the rotational speed of the rotor flux vector correspond to those of the speed of the stator flux vector fixed by the network [30].

$$
\begin{aligned}
& P_{R}=s P_{S} \\
& P_{G}=(1 \pm s) P_{S}
\end{aligned}
$$

with:

$P_{G}:$ The mechanical power provided by the generator

$P_{S}:$ The power provided by the stator

$P_{R}$ : The power supplied to the rotor

This imposes a generation of controlled active energy at a low penetration rate. The purpose of the transient analysis of the active energy at the output of the generators is to check their ability to withstand high network faults which explains their ability to generate sufficient electromagnetic torque to stabilize the frequency of the network. 


\subsection{Reactive energy analysis}

The same simulation will be carried out for the two case studies to visualize the generation of reactive energy by the fixed and variable generators. During a sudden fault, the generation of the reactive does not result from a mechanical force but results from a pure electric injection [31]. This transient analysis describes the impact of the DFIG reactive injection on the stability of the rotor angle of the synchronous generators.

\subsection{Stability of the rotor angle analysis}

Rotor angle stability is a dynamic phenomenon usually associated with changes in active and reactive power flows, that create angular separations between the synchronous units of the system with a very high penetration rate of wind energy [32]. This system will be subjected to a very large flow of active energy, which is essential for its stability. But how the DFIG injects reactive, the system can be critical for maintaining the angular stability of asynchronous systems. A transient simulation will be performed for the two previous cases to analyze the rotor angle separation of the synchronous systems.

\subsection{Short circuit faults calculation}

The transient stability of an electrical network is a critical element because the stability of the rotor angle of the synchronous generators depends on the configuration, the parameters and their proximity to a variable generator. Our system with $50 \%$ of wind turbine penetration impacts network behavior, and so the voltage stability is also affected. Our model has been tested under different short circuit faults calculated: Three-phase, two-phase grounded and single-phase. Calculations were made on MATLAB show in Table 1. This calculation allowed us to determine the most unfavorable default case or the most critical fault that is the single-phase between buses 9 and 6, and so the contingency created is the opening of the two circuit breakers flanking this line. In order to test the rotor stability of the synchronous generators during the integration of the DFIG, it was necessary to carry out a theoretical analysis of its impact on the active and reactive energy produced by the generators.

Table 1. Calculation of different type of short circuit faults

\begin{tabular}{cccccccccc}
\hline Branch & Fault 1 & $\begin{array}{c}\text { Fault 1 } \\
\text { Current } \\
\text { A (Pu) }\end{array}$ & $\begin{array}{c}\text { Fault 1 } \\
\text { Ang (Pu) }\end{array}$ & Fault 2 & $\begin{array}{c}\text { Fault 2 } \\
\text { Current } \\
\text { A (Pu) }\end{array}$ & $\begin{array}{c}\text { Fault 2 } \\
\text { Ang (Pu) }\end{array}$ & $\begin{array}{c}\text { Fault 3 } \\
\text { Fault 3 } \\
\text { Current } \\
\text { A (Pu) }\end{array}$ & $\begin{array}{c}\text { Fault 3 } \\
\text { Ang (Pu) }\end{array}$ \\
\hline Branch '2' '7' '1' & 3PB & 5,50132 & $-65,66$ & SLG & 4,01414 & $-73,42$ & DLG & 3,13404 & 102,1666 \\
Branch '4' '1' '1' & 3PB & 6,7567 & $-71,55$ & SLG & 8,99861 & 64,6057 & DLG & 2,90191 & $-98,086$ \\
Branch '5' '4' '1' & 3PB & 5,7298 & $-68,86$ & SLG & 9,02966 & 54,9561 & DLG & 2,85664 & $-100,574$ \\
Branch '6' '4' '1' & 3PB & 5,16053 & $-69,27$ & SLG & 9,97507 & 47,5893 & DLG & 2,97668 & $-101,441$ \\
Branch '7' '5' '1' & 3PB & 5,69642 & $-65,26$ & SLG & 10,0161 & 64,0301 & DLG & 2,94779 & $-92,3592$ \\
Branch '7' '8' '1' & 3PB & 5,69642 & $-65,26$ & SLG & 10,0161 & 64,0301 & DLG & 2,94779 & $-92,3592$ \\
Branch '8' '9' '1' & 3PB & 5,1556 & $-65,01$ & SLG & 10,0621 & 54,5991 & DLG & 2,94592 & $-95,6139$ \\
Branch '9' '3' '1' & 3PB & 4,90231 & $-66,87$ & SLG & 11,4792 & 52,1751 & DLG & 3,06461 & $-94,6968$ \\
Branch '9' '6' '1' & 3PB & 4,90231 & $-66,87$ & SLG & 11,4792 & 52,1751 & DLG & 3,06461 & $-94,6968$ \\
\hline
\end{tabular}

\section{CASE STUDY OF RTE IEEE 9-BUS STANDARD ELECTRICAL NETWORK AND ALGORITHM}

All simulations were performed on an IEEE 9 Bus network. This model is composed of 3 classic generators, 3 transformers and 3 charges. The total installed capacity in production is $319.63 \mathrm{MW}$ and the total capacity of the load is $315 \mathrm{MW}$. Plants 1,2 and 3 are conventional power plants or synchronous generators. The IEEE 9 Bus network is modeled on POWER WORLD as shwon in Figure 2. Two case of studies will be represented and tested:

a. The first case is a representation of the reference IEEE 9-bus network in which the generators 1, 2 and 3 are conventional productions or synchronous generators.

b. The second case is the IEEE 9-bus network where the generating station on bus 2 is replaced by a wind power plant with the same installed capacity, through the insertion of a global wind generator with an installed capacity of $163 \mathrm{MW}$.

The algorithm of this study is as follows in Figure 3. 


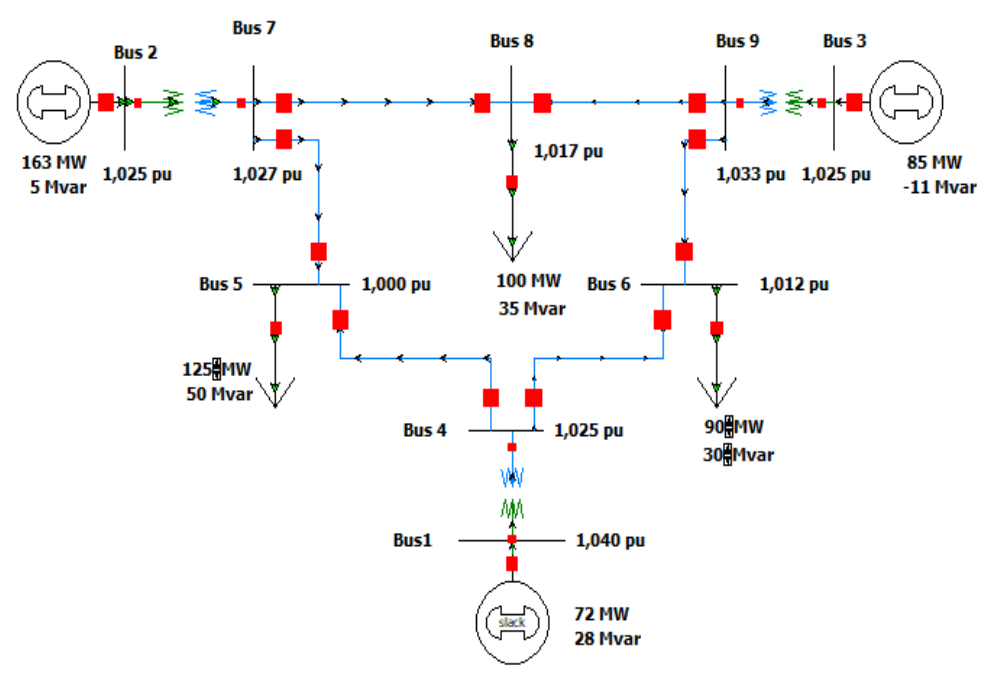

Figure 2. IEEE 9Bus network model on POWER WORLD

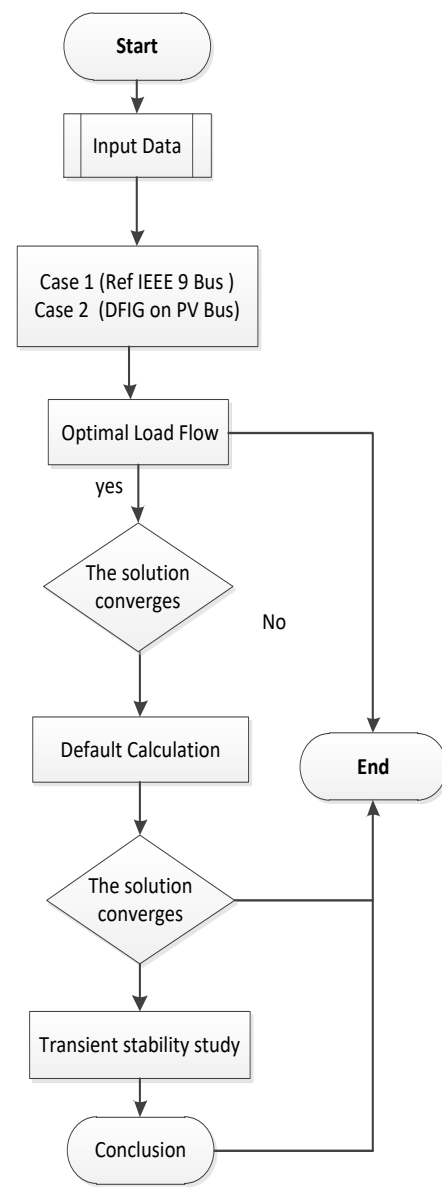

Figure 3. Algorithme of test of two case of studies

\section{SIMULATION RESULTS}

4.1. Active power simulation

The Figure 4 and 5 present the transient simulation of a single-phase fault of $11 \mathrm{pu}$ realized at time $\mathrm{t}=1 \mathrm{~s}$ at the IEEE 9Bus network before as shown in Figure 4 and after as shown in Figure 5 the replacement of the generator $\mathrm{N}^{\circ} 2$ by a DFIG of the same installed power. By comparing the two figures, we notice that 
there is a difference when the wind farms replace the synchronous plant. Indeed, when the DFIG is interconnected, it provides an electromagnetic current equivalent to an inertial response to the change of active power flow, due to the contingency of the single-phase fault between the buses 9 and 6 . This active flow generated relieves the other conventional generators. Thus, the rate of depreciation of the default is much lower than the reference case. This is visible on the Figure 5, after 10 seconds the generation of Active Energy becomes stable in all the fixed and variable energy generators.

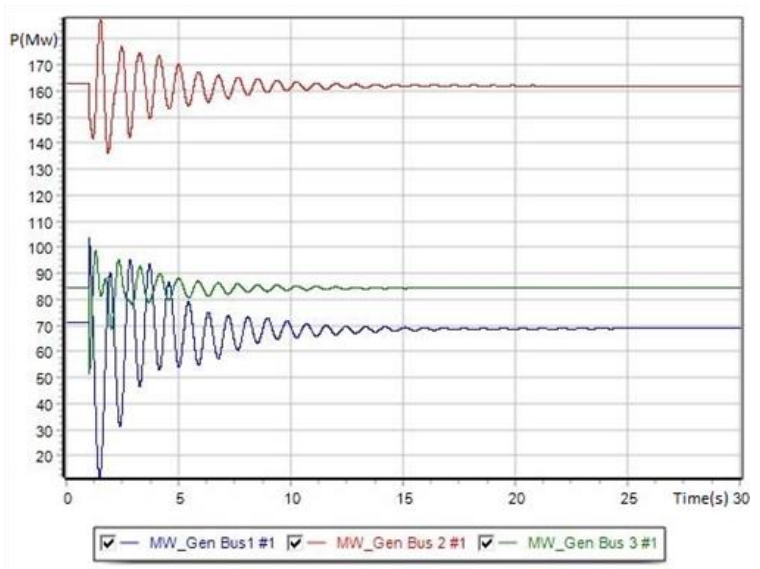

Figure 4. Active power generated by the generators in the first case of study

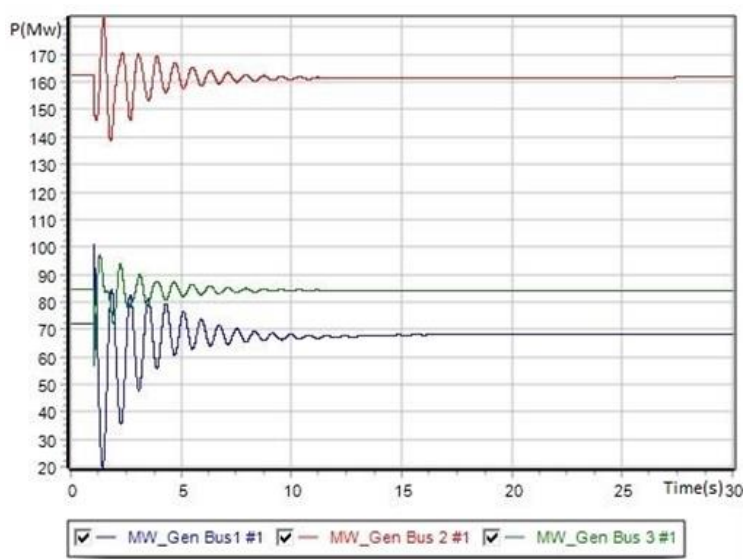

Figure 5. Active power generated by the generators in the second case of study

\subsection{Reactive power simulation}

The Figure 6 and 7 present the transient simulation of a single-phase fault of 11pu realized at time $\mathrm{t}=1 \mathrm{~s}$ at the IEEE 9Bus network before (Figure 6) and after (Figure 7) the replacement of the generator $\mathrm{N}^{\circ} 2$ by a DFIG of the same installed power. By comparing the two figures, we notice that there is a difference when the wind farms replace the synchronous plan. Indeed, the DFIG is able to inject reactive power into the network without taking into account the value of the active power which is clearly visible in the Figure 7 . This is 5 MVAR compared to the conventional power plant. After the fault, the damping time of the disturbance is almost the same and the DFIG cannot control the dynamic reactive energy since it injects more than 4MVAR in steady state, which disrupts the generation of reactive energy of constant speed plants.

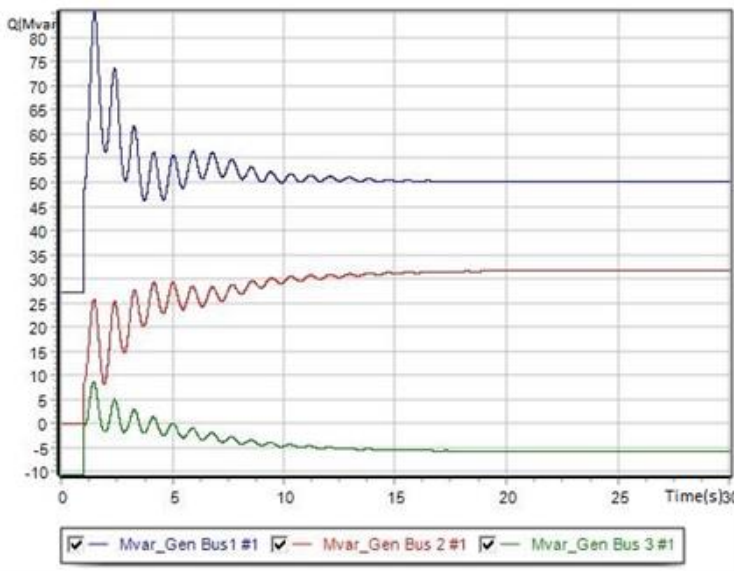

Figure 6. Reactive power generated by the three generators the first case of study

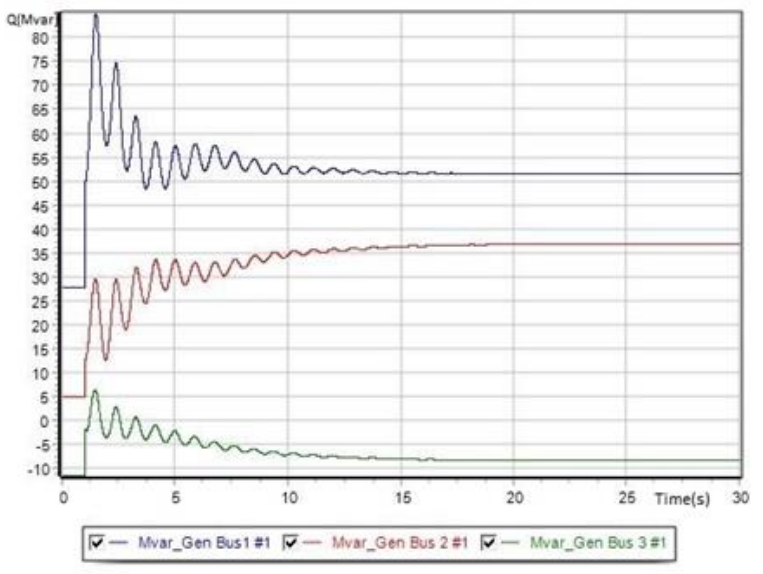

Figure 7. Reactive power generated by the three generators in the second case of study 


\subsection{Rotor angle simulation}

The Figure 8 and 9 present the transient simulation of a single-phase fault of $11 \mathrm{pu}$ realized at time $\mathrm{t}=$ $1 \mathrm{~s}$ at the IEEE 9Bus network before as shown in Figure 8 and after as shown in Figure 9 the replacement of the generator $\mathrm{N}^{\circ} 2$ by a DFIG of the same installed power. By comparing the two figures, we notice that there is a difference when the wind farms replace the synchronous plan. Indeed, at the time of the fault, the network interconnected with the DFIG serves to attenuate the fault by creating a holding power. We notice a great disturbance of the stator angle at time $t=1 \mathrm{~s}$ in the first case of study, in the second case we notice a small disturbance at the level of the stator angle, which makes it possible to avoid the separation of the stator angle and the production stop.

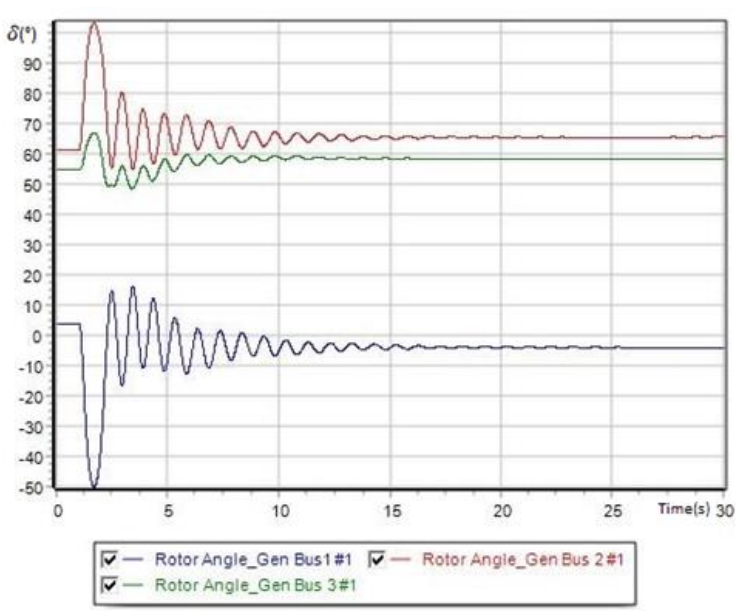

Figure 8. Rotor angle generated by the three generators in the first case of study

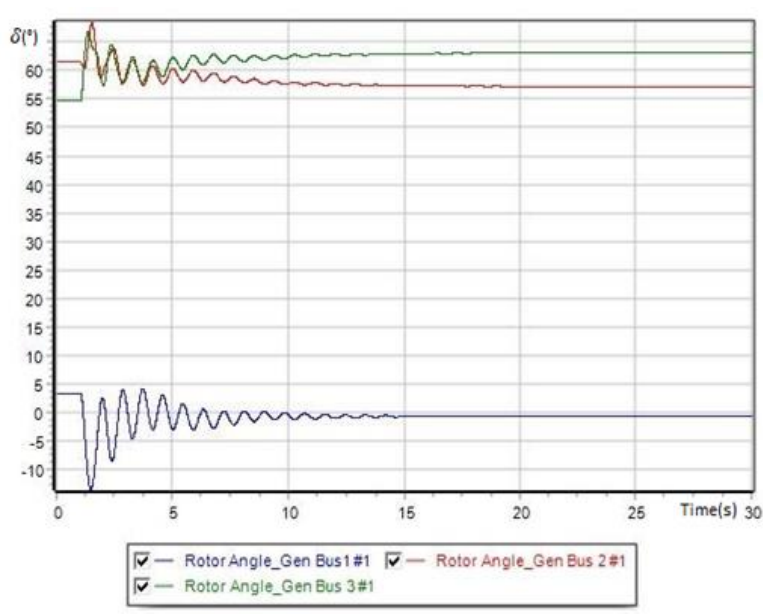

Figure 9. Rotor angle generated by the three generators in the second case of study

\section{CONCLUSION}

The optimal integration of wind power in the electrical networks can impact the stability of frequency and voltage as well as the instability of the rotor angle during faults. But the DFIG presents a very important asset which is the decoupled production between active and reactive power. This makes it possible to filter the disturbances due to the wind and avoid delivering disturbances to the network compared to other types of fixed speed wind turbines. Its ability to control the active flow relieves nearby synchronous generators, due to its very fast response time to produce active energy compared to the conventional generator during defects. However, its inability to limit the production of reactive power disrupts the dynamics of the reactive flow to the electrical network, which also impacts the generation of this power at the level of neighboring power stations during faults; This is an advantage for end-of-line low voltage antenna systems and an inconvenience for high reactive mesh networks. The DFIG also preserves the stability of the stator angle of the near conventional power stations and makes the fluctuations smooth due to defaults. This is clearly visible at penetration rates of around 50\%. Beyond this value, the addition of a FACTS for reactive control is essential in order to avoid overvoltage on the bus as well as the islanding of the wind turbine.

\section{ACKNOWLEDGEMENTS}

I would like to think of the members of ENSEM (LESE) for their help and their clarification

\section{REFERENCES}

[1] H. Zhang, et al., "Operation and control strategies of wind power in West Inner Mongolia Power Grid," IEEE Power and Energy Society General Meeting, 2012.

[2] G. Li, et al., "Transient stability studies of power system with shared transmission of wind power and thermal power," vol. 4, pp. 2.18-2.18, 2013.

[3] Y. Chen and Z. Liu, "Effect of large-scale wind farm on transient stability," Proceedings - International Conference on Electrical and Control Engineering, ICECE 2010, pp. 3680-3683, 2010.

[4] P. Kunder, "Power System Stability and Control," New York: McGraw-Hill, 1994. 
[5] Y. Ding, et al., "Short-term and medium-term reliability evaluation for power systems with high penetration of wind power," IEEE Transactions on Sustainable Energy, vol. 5, pp. 896-906, 2014.

[6] D. Han, et al., "The uncertainty and its influence of wind generated power on power system transient stability under different penetration," POWERCON 2014 - 2014 International Conference on Power System Technology: Towards Green, Efficient and Smart Power System, Proceedings, (Powercon), pp. 675-680, 2014.

[7] I. M. Dudurych, "The control of power system with a high wind power penetration," 2007 IEEE Lausanne POWERTECH, Proceedings, pp. 528-531, 2007.

[8] N. Cherfia and D. Kerdoun, "Wind Energy Conversion Systems Based On a DFIG Controlled By Indirect Vector Using PWM and SVM," International Journal of Electrical and Computer Engineering (IJECE), vol. 6, pp. 549559, 2016,

[9] M. E. Haque, et al., "Grid frequency analysis with the issue of high wind power penetration," 2013 International Conference on Electrical Information and Communication Technology, EICT 2013, 2013.

[10] B. Dolník, "Contribution to analysis of daily diagram of supply voltage in low voltage network: Working days versus non-working days," Electric Power Engineering (EPE) 2015 16th International Scientific Conference on, pp. 373376, 2015.

[11] F. Kamal and B. Chowdhury, "Impact of integrating DFIG and direct drive synchronous wind turbine generator on power system stability," 2017 North American Power Symposium, NAPS 2017, 2017.

[12] L. Meegahapola, et al., "Transient stability analysis of a power system with high wind penetration," Proceedings of the Universities Power Engineering Conference, 2008.

[13] J. Conto, "Grid challenges on high penetration levels of wind power," IEEE Power and Energy Society General Meeting, pp. 1-3, 2012.

[14] B. Mukhopadhyay, et al., "Voltage Compensation in Wind Power System using STATCOM Controlled by Soft Computing Techniques," International Journal of Electrical and Computer Engineering (IJECE), vol. 7, pp. 667680, 2017.

[15] D. Gautam, et al., "Impact of Increased Penetration of DFIG-Based Wind Turbine Generators on Transient and Small Signal Stability of Power Systems," IEEE Transactions on Power Systems, vol. 24, pp. 1426-1434, 2009.

[16] T. Littler and L. Meegahapola, "Characterisation of large disturbance rotor angle and voltage stability in interconnected power networks with distributed wind generation," IET Renewable Power Generation, vol. 9, pp. 272283, 2014.

[17] M. Moradzadeh, M., et al., "Impact of increased penetration of large-scale wind farms on power system dynamic stability - A review," 2015 IEEE 15th International Conference on Environment and Electrical Engineering, EEEIC 2015 - Conference Proceedings, pp. 1522-1526, 2015.

[18] E. Muljadi, et al., "Transient stability of the grid with a wind power plant," 2009 IEEE/PES Power Systems Conference and Exposition, PSCE 2009, 2009.

[19] Q. Yan, et al., "Influence of social identity on information release in microblog," Proceedings - 2012 International Conference on Intelligent Systems Design and Engineering Applications, ISDEA 2012, vol. 1, pp. 848-851, 2012.

[20] T. Tamilarasi and M. K. Elango, "Analysis of impact on rotor angle stability of DFIG wind turbines employing STATCOM," ICACCS 2016 - 3rd International Conference on Advanced Computing and Communication Systems: Bringing to the Table, Futuristic Technologies from Arround the Globe, 2016.

[21] Q. Wang, et al., "Impact of DFIG-based wind farm on transient stability of single machine infinite bus system," AsiaPacific Power and Energy Engineering Conference, APPEEC, (20120036110009), pp. 0-4, 2013.

[22] C. H. S. Prakash, et al., "A Novel Multi-Functional DSTATCOM with Distribution Generation using FRC Controller," International Journal of Electrical and Computer Engineering (IJECE), vol. 8, pp. 1373-1382, 2018.

[23] K. Rabyi and H. Mahmoudi, "Energy storage of DFIG based wind farm using D-STATCOM," International Journal of Electrical and Computer Engineering (IJECE), vol. 9, pp. 761-770, 2019.

[24] Erlich I., et al., "Modeling of Wind Turbines based on Doubly-fed Induction Generators for Power System Stability Studies," IEEE Trans. Power Systems, vol. 22, pp. 909-919, 2007.

[25] D. Han, et al., "A Real Application of Measurement-based Load Modeling in Large-scale Power Grids and Its Application,” IEEE Trans. on Power Systems, vol. 24, pp. 1756-1764, 2009.

[26] E. Muljadi, et al., "Effects of Variable-Speed Wind Turbine Generator on Stability of Weak Grid," IEEE Trans.Power Systems, vol. 22, pp. 29-36, 2007.

[27] L. L. Freris and A. M. Sasson, "Investigation of the Load-Flow Problem," Proceedings of IEE, vol. 115, pp. 1459$1470,1968$.

[28] R. Moreno, et al., "An integrated OPF dispatching model with wind power and demand response for day-ahead markets," International Journal of Electrical and Computer Engineering (IJECE), vol. 9, pp. 2794-2802, 2019.

[29] X. Yang, et al., "A Predictive Power Control Strategy for DFIGs Based on a Wind Energy Converter System," Energies, vol. 10, pp. 1098, 2017.

[30] Dinh Chung Phan, Trung Hieu Trinh "Maximum Power Extraction Method for a Doubly-fed Induction Generator Wind Turbine," International Journal of Electrical and Computer Engineering (IJECE), vol. 8, pp. 711-722, 2018.

[31] L/ F. Acevedo, et al., "Dynamic Voltage Stability Comparison of Thermal and Wind Power Generation with Different Static and Dynamic Load Models," International Journal of Electrical and Computer Engineering (IJECE), vol. 8, 2018.

[32] Q. Wei, et al., "Generator rotor angle droop control and its load-following characteristics," POWERCON 2016, 2016. 


\section{BIOGRAPHIES OF AUTHORS}

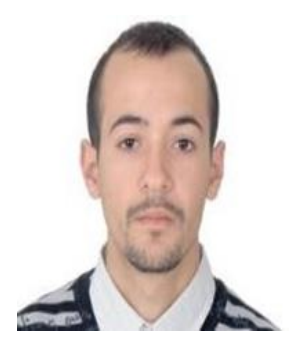

Anass Gourma was born in Marrakech, Morocco in 1989. He received his Engineering degree in 2013 in Electrical Engineering from the National School of Electricity and mechanics (ex: ENSEM), University Hassan II, Morocco. Since 2014, He has been a PHD student in Energy of Electrical Systems (ESE) engineering science laboratory of National School of Electricity and Mechanics (ENSEM), University Hassan II Aïn Chock, Casablanca, Morocco. His main research interests' deal with the control techniques of electrical systems used for renewable energy-based power systems.

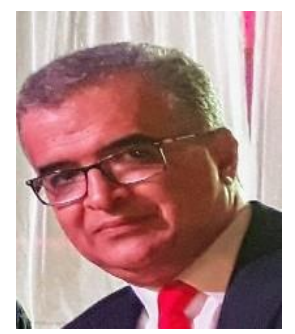

Abdelmajid Berdai holds a doctorate in engineering. He is currently Associate Professor and Chair of the Department of electrical engineering in the National School of Electricity and Mechanics, ENSEM, University Hassan II of Casablanca in Morocco where he has been since 1996. From 2002 to the present, he is a member of the Laboratory Building Technologies and industrial Systems (TCSI), Research Group: Electrical Systems (ESE). His research interests include Dynamic Simulation of Electric Machinery, Simulation and optimization of renewable energy systems, the use of quality power conversion for monitoring of electromechanical equipment state, Estimation of modes and diagnosis of induction motors base $\mathrm{d}$ on the quality of energy conversion, He has published numerous refereed papers in specialized journals and conferences. He served as a reviewer for Elsevier journal. He has been the Session Chair, TPC Chair and Panelist in several conferences.

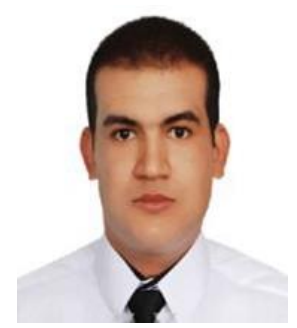

Moussa Reddak was born in Khouribga, Morocco in 1989. He received his Engineering degree in 2013 in Electrical engineering from the National School of Applied Sciences (ENSA), University Hassan I, Morocco. Since 2013, He has been a PhD student in Energy of Electrical Systems (LESE) engineering science laboratory of National School of Electricity and Mechanics (ENSEM), University Hassan II Aïn Chock, Casablanca, Morocco. His main research interest deals with the control techniques of electrical machines used for renewable energy-based power systems. 